\title{
Analyses and Improvement Options on Road Safety Issues in Beijing
}

\author{
Meiling Liu ${ }^{1, a}$ and Yuyan Liu, ${ }^{2}$
}

${ }^{1}$ School of Traffic and Transporation, Beijing Jiaotong University, Beijing 100044, China;

${ }^{2}$ School of Traffic and Transporation, Beijing Jiaotong University, Beijing 100044, China.

a1435054134@qq.com, b790828319@qq.com

\begin{abstract}
This paper analyzes the reasons that affect the road safety in Beijing from three aspects: motor vehicles, non-motor vehicles (represented by bicycle) and pedestrians. In view of the above problems, this paper puts forward corresponding improvement points. First, the relevant departments should improve laws and regulations to regulate people's behavior. Second, Increasing the number of the bicycle path is the first and most important step for solving bicycle safety problem. Finally, it is suggested to provide safety and awareness training with extra maintenance courses and road safety measures for motor vehicle drivers and cyclists. The article points out when accidents reduced to a certain extent, Laws revision and regulations has little effects and the lack of awareness about traffic safety is an underlying cause.
\end{abstract}

Keywords: Road safety issues; Awareness of traffic safety; Options of improvement.

\section{Introduction}

Nowadays, road traffic accidents have caused great numbers of casualties and a great deal of economic losses. Beijing, as the center of Chinese political, economic and cultural, is developing rapidly while the situation of road safety has not been improved apparently for the past five years.

As the increasing number of highway mileages, vehicles and urban inhabitants, road safety becomes more prominent. This article focuses on the potential elements that affect road safety, and then gives some options that could be used to improve the conditions.

\section{Data Analysis}

Given consideration to different kinds of traffic accidents happened in 2015(shown in Figure1), the article focused on three main aspects, motor vehicle, non-motor vehicle (represented by bicycle) and pedestrian.

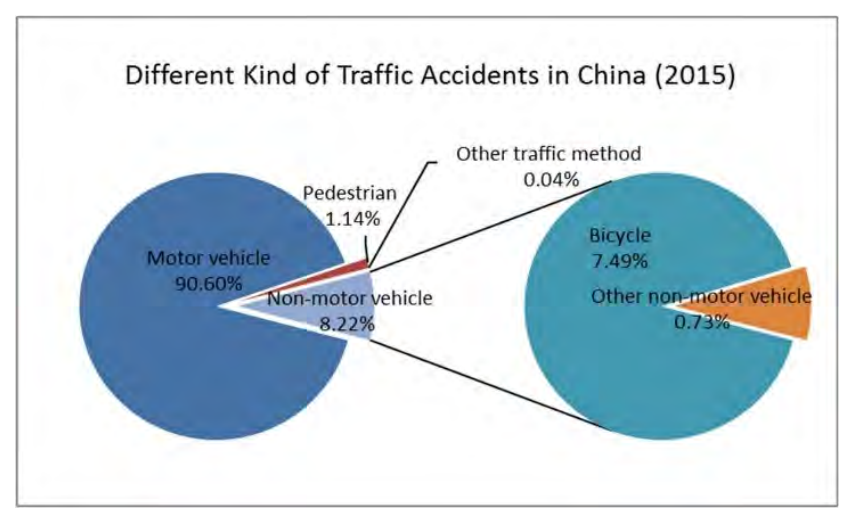

Fig. 1 Different Kinds of Traffic Accidents in China

As can be seen from figure1, the number of motor vehicle accidents is the dominant part of road traffic accidents with $90.6 \%$ in 2015 . And the second rank is the non-motor vehicle.

In order to find the specific safety data of bicycle, the article collected data from National Bureau of Statistics of the People's Republic of China and draw figure 2. 


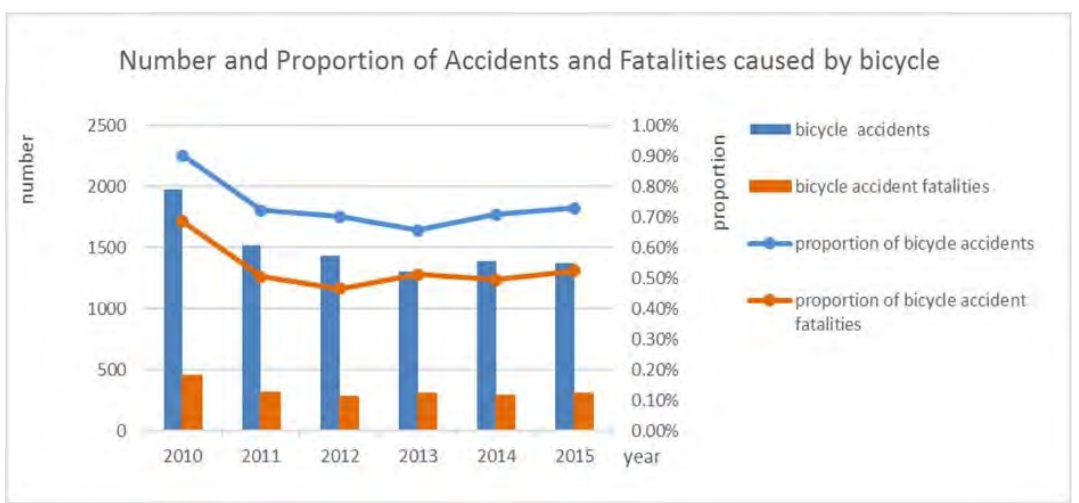

Fig. 2 Number and Proportion of Accidents and Fatalities Caused by Bicycle in China

As can be seen from Figure2, the number and proportion of road traffic accidents and fatalities caused by bicycles dropped significantly in 2010 and then showed an overall trend of stabilization from 2011 to 2015. However, since August 2016, shared cycling has appeared. The companies of shared bicycle such as OFO and Mobike has launched over 2,350,000 bicycles, and the bicycles were used by nearly 11,000,000 registered users in the city of Beijing until September 2017. With the explosive growth of shared bicycle, the accident rate of bicycle increased inevitably, showing that the lack of security guarantee for cyclists.

Pedestrian traffic system is also considered as a vulnerable group in the whole traffic system, even though it often be ignored. The article collected data from National Bureau of Statistics of the People's Republic of China, as shown in Figure3. It shows that the numbers of Pedestrian accidents, deaths and injuries are similar in recent years.

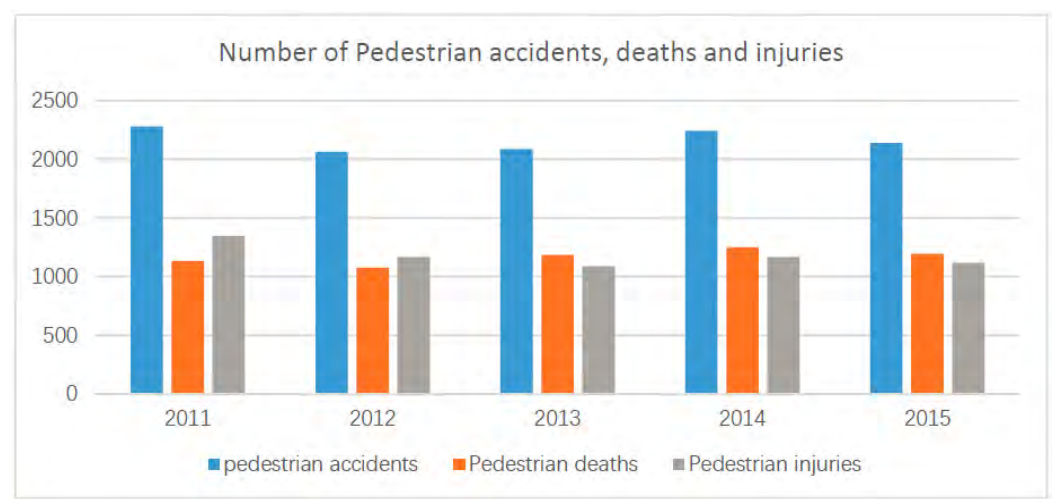

Fig. 3 Number and Pedestrian Accidents, Deaths and Injuries in China

\section{Key Issues of Road Safety}

\subsection{Motor Vehicles}

For motor vehicles, the key safety issues will be talked mainly from the following aspects: drivers and vehicles.

For drivers, traffic violation is the significant causation of incidents in Beijing. The government counted that almost $88 \%$ of accidents resulted from car drivers. Meantime, around $80 \%$ of deaths and $85 \%$ of injuries were caused by the same reason (Sun, 2014). Driver's illegal behaviors have greatly increased potential danger for others and themselves.

In terms of vehicles, a serious problem in Beijing is the rapidly increasing quantity of motor vehicles. Although the increment of the number is decreasing, the total number of vehicles is in the upward trend (see as Figure4). In the last few years, the ownership of motor vehicle in Beijing ranked first in the country. 


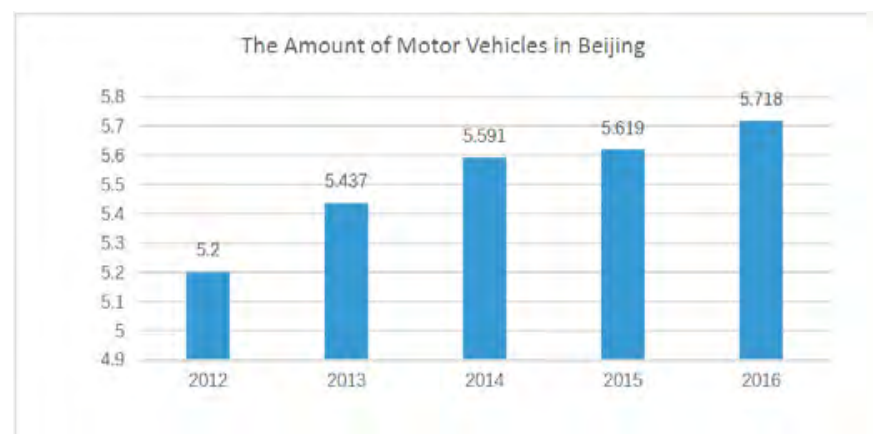

Fig .4 The Amount of Motor Vehicles in Beijing (China Statistics Press, 2017)

In addition, from the Percentage Change in the number of highway mileage and automobile in Beijing following (Figure5), it is obvious that the growth rate of motor vehicles is far exceeded that of highways. This means there would be heavier traffic congestion in junctions or on roads year by year, which would increase accident risks.

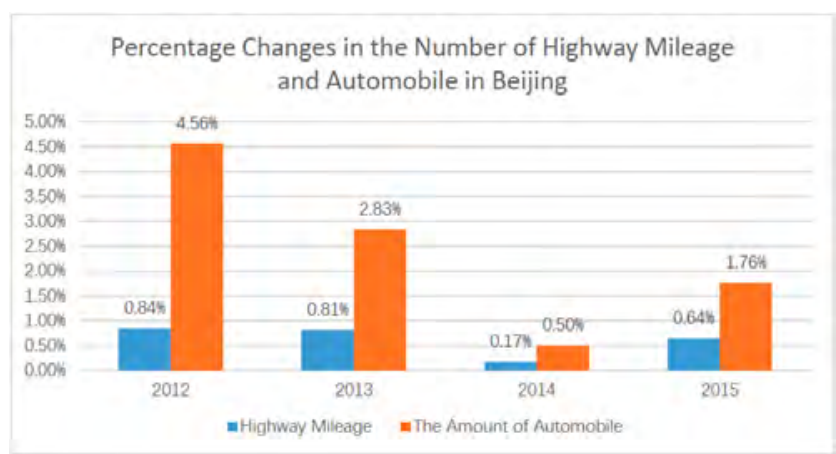

Fig. 5 Percentage Changes in Highway Mileage and Automobile in Beijing

\subsection{Bicycles}

The primary safety issue of cycling in Beijing is the incomplete bicycle infrastructure. First of all, the total length of the bicycle lanes within Beijing's fifth ring road is just about 700 kilometers at present, which still has serious occupation problems of illegal parking by motor vehicles. Secondly, unidentified and discontinuous right of the non- motorized lane may increase conflicts between bicycle and motor vehicles. For example, the conflicts between cyclists and the stopover buses stop at harbor bus station occurs frequently. Thirdly, most of the intersections do not have toucan crossing so that the cyclist will cross randomly on the street, which will cause safety problems as well.

Another issue is that the regulations are not been fully built. Regarding to the Law of the People's Republic of China on Road Traffic Safety, there is no rule related to the cyclist's costume or night riding, which is the most likely time for cycling accident. On the other hand, cyclists themselves are sources of safety hazards. Lacking of safety awareness can lead to dangerous behaviors. One phenomenon in bicycle riding is that some cyclists have less patience when crossing the stop line while the traffic light is still red. Another worrying situation is the cycling retrograde. In addition, random parking is also very common in Beijing.

\subsection{Pedestrian}

The first safety issue is pedestrian lack of traffic safety awareness. Many people consider that 'others are running the red light, so I can walk with them to cross the road'.

They treat other pedestrians as a safeguard and believe that they can protect themselves from traffic risks.

Another issue is that, compared with adult, children have more traffic risks. On one hand, children cannot judge traffic safety quickly and exactly; on the other hand, children are more difficult to be observed by drivers compared with adult. Especially in school areas, children rush out and play with 
their classmates when school is over so that ignoring the traffic safety, which could easily cause traffic accident.

\section{Options of Improvement}

\subsection{Laws and Regulations}

In order to decrease the occurrence of traffic violation, the Road Traffic Safety Law was modified in 2011, which increased penalties for illegal behaviors. For example, when a car driver is tested for drunk driving, he would lose his driving license or even cannot obtain the driver's license up to 5 years. The amendment was influential in reducing traffic accidents. From the number of motor vehicle accidents (see as figure 6), it is obvious that there is a clear decline in 2011. In addition, there is a downward trend with nationwide adjustment of traffic laws and regulations in 2014.

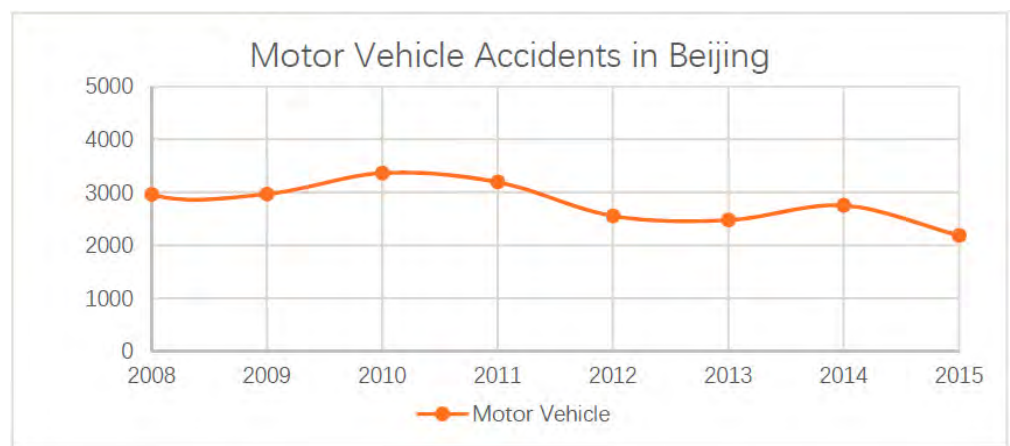

Fig.6 the Number of Motor Vehicle Accidents in Beijing (China Industry Information, 2017)

To control the number of motor vehicles on roads, the local government address some measures. One is limiting annual quantity of license plates issued, the other is limiting part of vehicles driving on the road. At present, approximately 150 thousand of license plates are issued every year so that motor vehicle ownership would be controlled within 6.3 million in 2020 . The government even implemented the regulation that limits two tail plate numbers driving out on weekdays in 2008, which can improve the environment to a certain degree, because it could decrease a tremendously amount of exhaust emissions.

When considering the laws of cycling. It is suggested firstly that correct sized helmet and visibility clothing should be wear. Then, rules about riding at night should be set. It can be learning from the Department for transport of UK that bicycles should install red rear reflector and amber pedal reflectors. White front and rear lights should be turn on at night to make sure other vehicles or pedestrians notice the cyclist and thus avoid collisions.

\subsection{Improvement of the Bicycle Infrastructure}

Increasing the number of the bicycle path is the first and most important step for solving bicycle safety problem. It is reported that the bicycle lanes in the Fifth Ring Road of Beijing will increase to 3200 kilometers by 2020 .

Expanding the cycle routes between the local communities could also be considered. It is suggested that using the double bicycle lanes will increase capacity of non-motor vehicle and avoid some safety problems. An extra lane can be chosen by different speed needed cyclists so that motor vehicles and bicycles could run in an orderly manner during peak hours in busy road sections.

In order to address the random crossing problem. It could refer to the UK's toucan crossing at junctions. In some area where the public parking space is not enough, it is recommended to use the double-decker parking frame to help increase cyclists parking space as well.

For conflict between regular riding bicycles and the stopover buses stopping at the harbor bus station. Increase a non-motorized laneway outside the bus station to isolate these two road users could ensure continuously passing through. 
In order to solve illegal parking problem of motor vehicle occupying non-motorized lane. It is feasible to install machines like guardrails to ensure the right of cyclists. Aiming at the problem of ambiguous right of road, color bicycle lanes can be used at locations where huge traffic volumes happens, such as junctions under overpass. Besides, bicycle signs and markings can be adopted at some small traffic volume sites.

\subsection{Education}

It is suggested to provide safety and awareness training with extra maintenance courses and road safety measures for motor vehicle drivers and cyclists. It is also necessary to provide bicycle proficiency training for children to protect them from the early age. Apart from that, schools can always invite traffic policeman to give a traffic safety lesson for the students, which can teach students pedestrians how to protect themselves effectively.

\section{Conclusion}

Laws revision and regulations could not address all issues. When accidents reduced to a certain extent, these approaches have little effects. On the one hand, some people are still breaking traffic laws and regulations because they believe that they are lucky enough to avoid catching by police or happen an accident. Hence, the lack of awareness about traffic safety is an underlying cause. Education is not enough.

On the other hand, traffic demands are greatly increasing with more and more people moving in Beijing. Commuters and students prefer to work or school by car in weekdays. People would find other methods to cope with these regulations, such as purchase more cars so that they have different plate numbers. Developing public transportation to split demands from private cars to other transportation modes is probably an approach to control motor vehicle ownership. However, attracting inhabitants to choose urban public transportation is relatively difficult.

To summary, there are many problems for traffic safety in Beijing. Although the government has attempted to implement various methods to ease these situations, the results are less than satisfactory. The article suggests that the key barriers are people's concept and awareness. Only when people have enough traffic safety consciousness, the traffic modes could be changed, and it will create a safer traffic environment.

\section{References}

[1]. Beijing Bureau of Statistics. (2017). Beijing Statistical Yearbook. Beijing: China Statistics Press. Information on: http://edu.bjstats.gov.cn/.

[2]. China Industry Information. (2017). Analysis on the Trend of Motor Vehicle Ownership in Beijing. Information on: http://www.chyxx.com/industry/201703/502573.html.

[3]. Sun, S. (2014). Current Situation Analysis and Countermeasures of Road Traffic Safety in Beijing. Road Traffic and Safety, 32-35.

[4]. National Bureau of Statistics of the People's Republic of China. Traffic Accidents. Information on: http://www.stats.gov.cn/.

[5]. Yuelin Wang. (2015). How wide is the bike lane? Information on: http:// www. bjsdfz. com/ readnews.aspx?newsid $=5290$.

[6]. Cycling UK's Cycling Statistics. Information on: https:// www. cyclinguk. org/ resources /cycling-uk-cycling-statistics. 